\title{
Science \& Wine: The Wine of the Future
}

\author{
Paula Silva \\ psilva@icbas.up.pt | Laboratory of Histology and Embryology, Institute of Biomedical Sciences Abel \\ Salazar, Rua de Jorge Viterbo Ferreira nㅡㅡㄹㄹ, 4050-313 Porto, Portugal.
}

\section{Letter from Academia}

\begin{abstract}
Worldwide wine production has a great cultural and economic importance. A multidisciplinary approach is necessary to improve wine quality. The First Science \& Wine World Congress was planned to be a discussion forum considering the wide wine research spectrum. The idea attracted more than 100 attendees most of which scientists. Wine sector professionals missed the call, which emphasize the necessity of implementing strategies to approach those to the academy. Among the topics discussed, the effects of wine in health was pointed out as a priority. Global forums are a good approach to discuss wine in a holist mode.
\end{abstract}

Keywords. Wine, Vine, Viticulture, Technology, Science Communication, Oenology.

Cite paper as: Silva, P., (2019). Science \& Wine: The Wine of the Future - Letter from Academia, Journal of Innovation Management, www.open-jim.org, 7(1), 21-25. HANDLE: https://hdl.handle.net/10216/119830; DOI: https://doi.org/10.24840/2183-0606_007.001_0003 


\section{Introduction}

Humans have produced wine for thousands of years. Wine production is an important socioeconomic activity and one of the most dynamic and competitive ones in the agro-food market. Due to its importance, wine is in the center of study of different sciences (Fig. 1). The scientific discussion among experts of each scientific field is very important to validate terminology, methodologies, results, to find solutions and to propose future research. An integrated discussion about wine, however, is crucial to the evolution of each and of all areas. The wine of the future must be a healthy, authentic, enjoyable, and profit product, which results from sustainable viticulture's and produced with advanced technology. Therefore, it is important to promote a discussion about wine, including points of view such as: viticulture, oenology, environmental sciences, health sciences, informatic, enginery, economy among others. Is also crucial that this discussion includes academics and wine professionals. In my opinion, a gap between academy and wine sector still exists. The crosstalk only happens when the involvement of the other part is essential to attain their own goals. Nowadays researchers have a great pressure to publish and in most of the cases they do not have time to interact with people that could help to project better experimental designs. I agree with the ones that affirm that this pressure to publish pushes down the quality of research. On the other hand, the main concern of winemakers is to have to make money, so they only ask academy help when they need to find a solution to increase their profit. Additionally, it is essential to mention that public institutions, which could have a significant intermediate role between academy and winemakers, are over-occupied with bureaucratic issues and have fewer and fewer employees. In January 2018 it was launched the web platform Science \& Wine (http://science-and-wine.com/), a science communication project with the main goal of sharing scientific results using simple language. This project also aims to promote networking between the academy and the wine sector. After one year of the web platform launch, I decided to organize the First Science \& Wine World Congress with the same philosophy and that deserved the support of University of Porto (UPorto) and of International Organization of Vine and Wine (OIV). In this letter I will summarize some results discussed in this Congress.

\subsection{First Science \& Wine World Congress: some data}

In the First Science \& Wine World Congress were present 115 attendees from 16 different countries. Among this were represented 46 universities/research centers, 15 private companies, and two public institutes. Thirty-four works were presented as oral communication and 40 as a poster, which totalizes 74 presentations. The works were divided into the following research areas: wine traceability and authenticity; wine chemistry and sensorial wine experience; wine analysis; vine and wine technology; wine and health and wine waste. From this data, we can conclude that this first congress was a success in the number of attendees and the diversity of works presented. The number of non-academics, however, was very low, which confirms the need for stronger initiatives to bring these two parts together. New strategies to increase the relationship of the sector with the academy should be considered and implemented. 


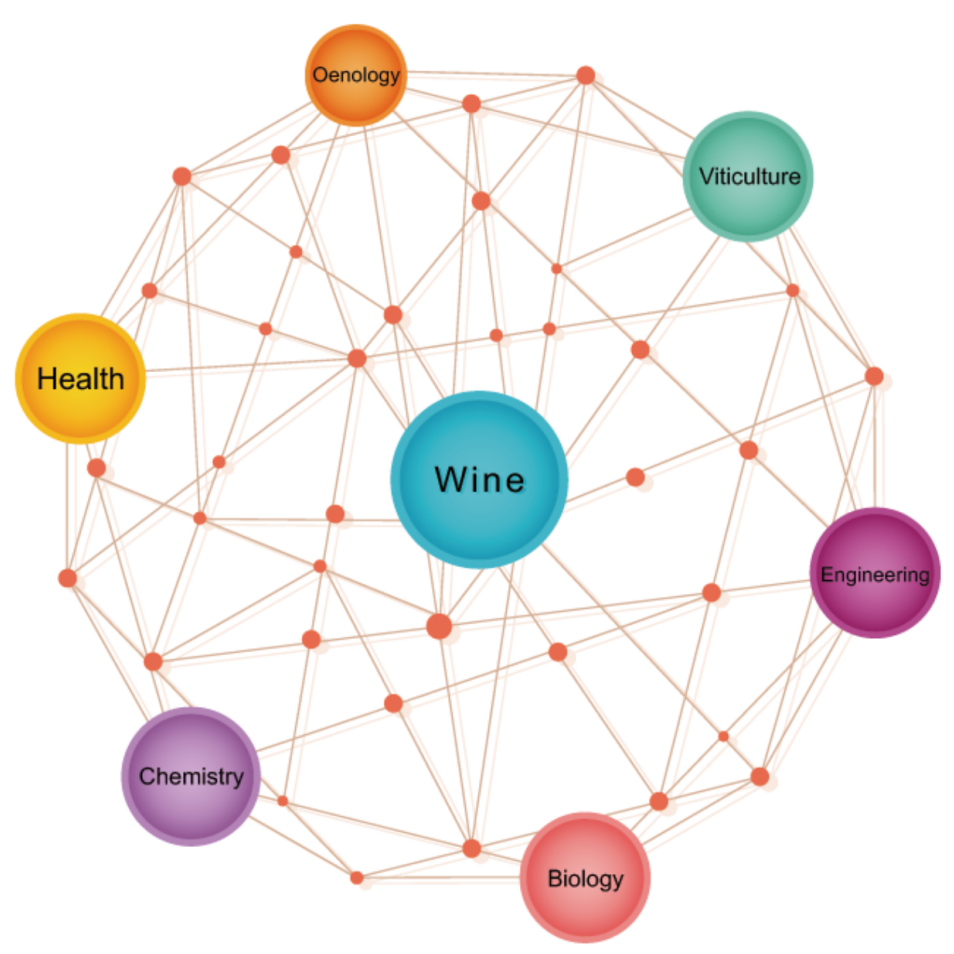

Fig. 1. Some research areas in which wine is the study subject.

\subsection{First Science \& Wine World Congress: The wine of the future}

The wine of the future will be produced by applying high advanced technologic resources in different production phases. Starting with their use to identify grapevine varieties within demarcated territories. In Portugal, University of Trás-os-Montes e Alto Douro developed mySense, a tool that incorporates artificial intelligence to identify the varieties that exist in Douro Demarcated Region. Mysense is being tested by Instituto dos Vinhos do Douro e Porto, to achieve a useful tool to support both its regulatory and inspecting responsibilities. This networking collaboration between researchers and public institutions are crucial to the future of wine sector. Mysense is based on the submission of up to 6 images framing the element to identify, these are then analyzed by a Distributed Computational Intelligence Module (DCIM) that provides a probable identification. DCIM is based on a convolutional neural network - Xception architecture - initially trained using a data set acquired in Douro Demarcated Region and periodically improved by incorporating new validated observations. Results obtained thus so far allow to conclude that artificial intelligence techniques can indeed contribute to both quick and precise grapevines variety identification, endowing viticulture stakeholders with straightforward technological tools that will help support their regular activities. Regarding viticulture, GIS-based clustering tools will be frequently used for characterization and implantation of vineyards aiming the production of better-quality wines. Nanotechnology also has a promisor future in wine production. With nanotechnology will be possible to produce sensible sensors, antimicrobial compounds, and to improve some processing techniques. In last decade electronic "tongues" have been developed to analyze wine without the need of separating it into simple components. One of those "tongues" 
was formed by phthalocyanines combined with biosensors (containing enzymes such as glucose oxidase or tyrosinase and phthalocyanines as electron mediators). This sensor array, coupled with pattern recognition techniques, can distinguish the red wines and red grapes on account of their chemical nature. In the near futures, it is necessary to reduce electronic tongues costs to be possible its regular use.

In the future, consumers want to be sure that the wine is authentic, therefore is important to adopt some approaches to detect wine adulteration/mislabeling practices. Wine authenticity confirmation can only be achieved through a multidisciplinary approach involving both the geographical provenience and grapevine varietal identification using DNA-based methodologies. Furthermore, certification and control procedures can be also improved using a GC-IRMS approach to investigate the presence of stable isotope ratios.

Winemakers must produce wine, considering that in the consumer decision-making process is involved in emotional engagement and cognitive interest. Considering the intrinsic features of wine, some results show that the smell phase involves more emotional engagement than the taste phase, which involves more cognitive interest. In the sensorial context, aromatic quality of wines is a very important wine characteristic. Therefore, it is important to support research aimed to increase wine aromatic quality. As shown in this Congress, the latter is affected by grape origin, light exposure, bottle stopper, oak chips and yeast strain use. In the future neuromarketing should consider the environment where wine will be consumed, since, for example, a wine could lead to different sensorial experiences according to the music that is listening. Future consumers must know wine health effects. This is a crucial aspect for the future of the wine sector, where all must work together to understand more about it and is urgent to define joint communication strategy to avoid misunderstandings.

\subsection{Conclusion}

The main conclusion of First Science \& Wine World Congress is that the wine of the future must be designed by a multidisciplinary team. Considering that terroir affects from grape growing to wine production a holistic approach must be considered. This First Congress has also shown that researchers want to participate in these discussions and answer positively to these challenges. Wine professionals, however, must be motivated to participate in this type of discussions and must be encouraged to include scientific research among their priorities. This congress showed that great advances are being attained in different areas such as viticulture, vine and wine technology, wine analysis and sensorial experience. More efforts are necessary to clarify the effects of wine in health, since contradictory messages are often spread by the media. These discussions are most welcome to promote critical thinking, to get new research perspectives, to encourage networking and to support political decisions. 


\section{Biographies}

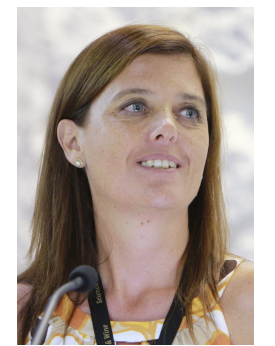

Paula Silva. Assistant Professor in the Laboratory of Histology and Embryology, Department of Microscopy, in the Institute of Biomedical Sciences Abel Salazar (ICBAS) of University of Porto (UPorto). Teaching experience covers: Histology and Embryology (Human and Comparative), Animal Models of Human Disease, and Science Communication. Director of the continuing training course "Science communication - Life and health sciences" (6ECTS) and of the continuing training unit "Animal Models of Human Disease" (6ECTS). She obtained her PhD in Biomedical Sciences in UPorto. Paula Silva presents in her CV 19 original articles published in journals indexed in the Science Citation Index (SCI), 1 book chapter, participation in some I\&DT projects, and numerous works in many national and international congress. At present, her main research topic is the influence of moderate consumption of wine on chronic diseases, particularly, neurodegenerative diseases. Editor of the Science \& Wine blog (http://science-and-wine.com/).http://orcid.org/00000001-7204-6006. h-index: 8.

\section{ISSN 2183-0606}

http://www.open-jim.org

http://creativecommons.org/licenses/by/3.0 